\title{
Relationship of Prenatal Care to Poor Postnatal Outcomes in Infants Requiring Neurodevelopmental Assessment
}

\author{
Juniper J. Lee-Park, Trevor L. Valentine \\ MedStar Georgetown University Hospital, Washington, DC, USA \\ Email: ljunip2@vt.edu
}

How to cite this paper: Lee-Park, J.J. and Valentine, T.L. (2019) Relationship of Prenatal Care to Poor Postnatal Outcomes in Infants Requiring Neurodevelopmental Assessment. Open Access Library Journal, 6: e5922. https://doi.org/10.4236/oalib.1105922

Received: November 14, 2019

Accepted: December 21, 2019

Published: December 24, 2019

Copyright $\odot 2019$ by author(s) and Open Access Library Inc.

This work is licensed under the Creative Commons Attribution International License (CC BY 4.0).

http://creativecommons.org/licenses/by/4.0/

\section{(c) (i) Open Access}

\begin{abstract}
Objectives: We aimed to determine whether complete lack of prenatal care (NPC: No Prenatal Care) is associated with social, as well as medical vulnerability of the mother-infant dyad and how it affects neurodevelopmental outcomes in infants. Methods: Selected social determinants indicative of the family's social vulnerability, including intrauterine drug exposure (IUDE) of the infant and child protective service (CPS) involvement before discharge, were compared between a cohort of infants whose mothers sought prenatal care and their counterparts with complete lack of PC. Also, selected medical conditions indicative of an infants' medical vulnerability, including cardiovascular, pulmonary, and neurological diagnoses, were compared between two groups. Fifty seven infants in a neonatal intensive care unit (NICU) and 10,483 infants in the newborn nursery at an urban level III hospital who were admitted between 2016 and 2018 were retrospectively evaluated. Results: Higher social vulnerability was observed in NPC group as indicated by a more prevalent history of IUDE and higher rates of CPS involvement. NPC mothers were also more likely to be Medicaid recipients and younger. Infants in both the NICU and the newborn nursery also had a lower mean birth weights for gestational age, lower APGAR scores as well as poorer respiratory and neurological outcomes. Conclusion for Practice: Prenatal care can have long lasting benefits to the mother-infant dyad by lowering the risks associated with pregnancy, increasing birth weights and lowering the risk for developing pulmonary and neurological complications. Promoting the family's active engagement in prenatal care can also serve as an easily achievable first step in minimizing health disparities.
\end{abstract}

\section{Subject Areas}

Pediatrics 


\section{Keywords}

Prenatal Care, Neurodevelopmental Outcomes, Mother-Baby Dyad

\section{Introduction}

Prenatal care (PC), defined as one or more visits before admission to an obstetric unit for delivery [1], where pregnancy history, physical exam, appropriate laboratory studies, and imaging are obtained, is crucial for the wellbeing of newborns. Furthermore, it helps clinicians address preventable risk factors in the maternal history such as maternal substance use that contribute to poor health outcomes of infants [2] [3] [4].

Numerous studies have shown a strong association between a lack of prenatal care and an infant's poor health outcome including low birth weight and prematurity [5] [6] [7] [8] [9]. However, a better understanding of how prenatal care relates to both social and medical wellbeing of a child would help us to understand obstacles to effective implementation. We aimed to show how a complete lack of prenatal care is associated with two types of determinants. The first determinant is social vulnerability, defined as certain conditions that impact an infant's physical and mental wellbeing. Examples include maternal substance use and child protective service (CPS) involvement before discharge and a requirements for further social work or case management involvement at the birth hospital [10] [11] [12]. The second determinant is medical vulnerability, defined as identified conditions complicating the infant's physical wellbeing later in life. For this, we specifically focused on neurodevelopmental outcomes, because poor neurodevelopmental outcomes tend to chronically derange a child's long-term health [13]. We hypothesized that there would be a strong association between certain social and medical, and especially neurodevelopmental characteristics of mother-infant dyads and complete lack of PC.

For this study, patients admitted to an urban level III neonatal intensive care unit (NICU) and an affiliated well-baby nursery from surrounding communities where the percentage of mothers with no prenatal care is higher than for the country as a whole in 8 of its 13 jurisdictions were retrospectively revisited. Also by looking at an area where the population is particularly vulnerable, we aimed to identify some of the root causes behind a history of no prenatal care in order to suggest interventions that may serve to prevent poor neurodevelopmental outcomes.

\section{Methods}

\subsection{Study Design and Data}

The medical records of 57 infants $(n=57)$ in the neonatal intensive care unit (NICU) and ten thousand, four hundred and thirty-eight infants $(n=10,483)$ in the newborn nursery at an urban level III hospital admitted between 2016 and 
2018 were retrospectively reviewed in order to identify associations between an absence of prenatal care and selected pre-existing social determinants of the family (intrauterine drug exposure [IUDE], Child Protective Service [CPS] involvement, mother's parity and basic demographic data) as well as the infants' postnatal medical conditions (Cardiovascular conditions [CV], presence of respiratory distress syndrome [RDS], bronchopulmonary dysplasia [BPD], chronic lung disease [CLD], requirement for central nervous system [CNS] drugs, intraventricular hemorrhage [IVH], periventricular leukomalacia [PVL], retinopathy of prematurity [ROP], and a failed routine audiology evaluation). Data were extracted from electronic medical records. Institutional Review Board approval was obtained for this study.

\subsection{Analysis}

The aforementioned association was assessed using Fisher exact and unpaired $t$ tests. Chi-square analysis was performed for aforementioned outcomes adjusted for basic demographic information, including mother's age, other's ethnicity, gestational age, birth weight, 1-min, 5-min APGAR scores, and insurance status. Distribution patterns of these data were plotted using the frequency feature of statistical analysis software, including Excel (Microsoft, USA) and JMP Pro 12 (SAS Institute Inc., USA). Concerning possible collinearity between the variables, prematurity and low birth weight were not adjusted for each other and assessed individually. Prevalence of primary diagnoses obtained from the medical records was compared by the means of prevalence and odds ratios (OR: $95 \%$ $\mathrm{CI}$ ). Percentages of selected social determinants were compared using Chi-square analysis $(\mathrm{df}=1, \mathrm{a}=0.05)$.

\section{Results}

\subsection{Characteristics of the Mothers}

A total of 57 infants in the NICU and 10,438 infants in the newborn nursery with complete documentation of prenatal, intra-natal, and post-natal care status in the history and physical, discharge summary, and social work documentation were eligible for inclusion and further analysis. In the NICU, a total of 50 infants (88\%) were born to mothers with prenatal care and 7 infants (12\%) were born to those without. In the newborn nursery, a total of 10,250 infants (98\%) were born to mothers with prenatal care and 188 infants $(2 \%)$ were born to those without. In Table 1, we listed the baseline demographic background of the mothers. As shown, there was a wider range of ethnicities represented in the PC group and a greater presence of African American mothers in NPC group. In the NICU, 72\% of the mothers in the NPC group were dependent on government subsidized insurance (i.e. Medicaid) or completely uninsured at the time of childbirth, as opposed to $64 \%$ in PC group. In the nursery, 97\% of those with NPC were dependent on government-subsidized insurance or uninsured, compared to $75 \%$ in the PC group. In the NICU population, where a mother's young age was a risk factor 
Table 1. Demographic data of the mothers.

\begin{tabular}{ccccc}
\hline & $\begin{array}{c}\text { Prenatal Care } \\
\text { NICU }\end{array}$ & $\begin{array}{c}\text { No Prenatal Care } \\
\text { NICU }\end{array}$ & $\begin{array}{c}\text { Prenatal Care } \\
\text { Nursery }\end{array}$ & $\begin{array}{c}\text { No Prenatal Care } \\
\text { Nursery }\end{array}$ \\
\hline Ethnicity & & & & \\
African American & $30 / 50(60 \%)$ & $7 / 7(100 \%)$ & $6028 / 10,250(62.83 \%)$ & $158 / 188(89.77 \%)$ \\
Caucasian & $6 / 50(12 \%)$ & & $1287 / 10,250(13.41 \%)$ & $5 / 188(2.84 \%)$ \\
Hispanic/Latino & $4 / 50(8 \%)$ & & $1562 / 10,250(17.25 \%)$ & $10 / 188(5.92 \%)$ \\
Asian & $2 / 50(4 \%)$ & & $129 / 10,250(1.34 \%)$ & $0 / 188(0.00 \%)$ \\
Other & $4 / 50(8 \%)$ & & $588 / 10,250(5.16 \%)$ & $3 / 188(1.47 \%)$ \\
Unknown & $4 / 50(8 \%)$ & & & \\
Mother's age & $31.8(\mathrm{sd}=7.1)$ & $29.8(\mathrm{sd}=4.9)$ & $29.0(\mathrm{sd}=6.1)$ & $27.6(\mathrm{sd}=6.5)$ \\
Insurance & & & & \\
Uninsured & $3 / 50(6 \%)$ & $0 / 7(0 \%)$ & $1313 / 10,250(28.56 \%)$ & $67 / 188(47.18 \%)$ \\
Medicaid, Medicare & $29 / 50(58 \%)$ & $5 / 7(72 \%)$ & $2150 / 10,250(46.77 \%)$ & $71 / 188(50 \%)$ \\
Private insurance & $18 / 50(36 \%)$ & $2 / 7(28 \%)$ & $1134 / 10,250(24.67 \%)$ & $4 / 188(2.82 \%)$ \\
\hline
\end{tabular}

for pre-term labor, the mean age for mothers was higher in prenatal care group (31.8 y), compared to no prenatal care group (29.8 y). The distribution of mothers' ages shown in Figure 1 suggests that a higher percentage of NPC group participants were indeed in the younger age categories.

\subsection{Characteristics of the Infants}

There were remarkable differences in social determinants between NPC and PC groups in both the NICU and well-baby nurseries as shown in Table 2. In the NICU, $71 \%$ of the NPC group infants, as opposed to $10 \%$ of PC group infants, were exposed to drugs while in utero, a statistically significant difference. In the newborn nursery, $16 \%$ of NPC infants, compared to $1 \%$ in the PC group, were exposed to substances in-utero. In the NICU, a significantly higher percentage of infants in the NPC group ( $42 \%$ in the NPC group versus $12 \%$ in PC group) were born to mothers who were subjected to a Child Protective Service (CPS) investigation. In the newborn nursery, the same pattern was appreciated (25\% in NPC versus $2 \%$ in PC). Regarding the medical vulnerability of the infants, it was first noted that infants without prenatal care in the well-baby nursery tended to be transferred to NICU as a result of clinical deterioration more often than their counterparts with prenatal care. In both the NICU and newborn nursery, a higher percentage of the NPC group infants had lower 1-minute APGAR scores and lower birth weights when compared to the PC group of infants (Table 3). In the NICU, where birth weight is a crucial prognostic determinant, birth weight distribution showed that a higher percentage of NPC infants were populated at the lower end of the weight range when compared to PC groups. Interestingly however, in the NICU, where gestational age is as crucial as birth weight to determining the clinical course, the gestational age distribution was similar between 


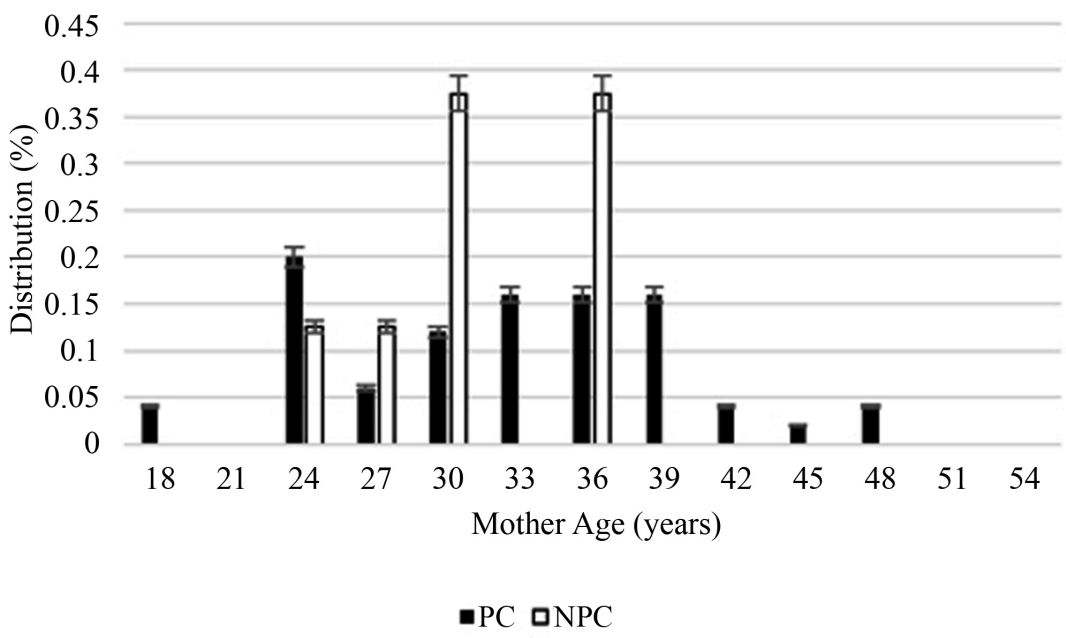

Figure 1. Maternal age distribution NICU. PC $(n=50)$ : mean 31.9; $\mathrm{sd}=7.1$, NPC $(n=7)$ : mean 29.8; sd $=4.9$.

Table 2. Summary of social determinants.

\begin{tabular}{cccc}
\hline Social Determinant & Prenatal Care & No Prenatal Care & p-Value \\
\hline Multiparous birth & NICU 28/50 (56\%) & $6 / 7(85.7 \%)$ & 0.133398 \\
IUDE & NICU 5/50 (10\%) & $5 / 7(71 \%)$ & $\mathbf{0 . 0 0 0 0 6 3 ^ { * * * }}$ \\
& Nursery 164/10,250(1.63\%) & $29 / 188(16.48 \%)$ & $<0.0001$ \\
CPS involvement & NICU 6/50 (12\%) & $3 / 7(42 \%)$ & $\mathbf{0 . 0 3 5 9 9 * *}$ \\
& Nursery 288/10,250 (2.81\%) & $47 / 188(25.00 \%)$ & $<0.0001$ \\
\hline
\end{tabular}

Table 3. Summary of primary diagnoses.

\begin{tabular}{|c|c|c|c|}
\hline Primary dg & Prenatal Care & No Prenatal Care & p-Value \\
\hline $\begin{array}{c}\text { Transferred } \\
\text { from Nursery to NICU }\end{array}$ & Nursery $1024 / 10,250$ (9.99\%) & $33 / 188(17.55 \%)$ & 0.0007 \\
\hline Cardiovascular & NICU 13/50 (26\%) & $0 / 7(0 \%)$ & 0.2592 \\
\hline (PFO, ASD, VSD, PDA) & Nursery $28 / 10,250(0.27 \%)$ & $1 / 188(0.53 \%)$ & 0.4101 \\
\hline RDS & $\begin{array}{c}\text { NICU } 37 / 50(74 \%) \\
\text { Nursery } 64 / 10,250(0.62 \%)\end{array}$ & $\begin{array}{c}7 / 7(100 \%) \\
2 / 188(1.06 \%)\end{array}$ & $\begin{array}{l}0.2592 \\
0.3341\end{array}$ \\
\hline $\mathrm{BPD} / \mathrm{CLD}$ & $\begin{array}{c}\text { NICU 7/50 (14\%) } \\
\text { Nursery } 29 / 10,250(0.28 \%)\end{array}$ & $\begin{array}{c}2 / 7(28 \%) \\
1 / 188(0.53 \%)\end{array}$ & $\begin{array}{l}0.3340 \\
0.4208\end{array}$ \\
\hline CNS medications & $\begin{array}{c}\text { NICU 9/50 (18\%) } \\
\text { Nursery } 212 / 10,250(2.11 \%)\end{array}$ & $\begin{array}{c}0 / 7(0 \%) \\
16 / 188(9.09 \%)\end{array}$ & $\begin{array}{c}0.4121 \\
<0.0001\end{array}$ \\
\hline IVH/PVL & $\begin{array}{c}\text { NICU } 14 / 50(28 \%) \\
\text { Nursery } 8 / 10,250(0.08 \%)\end{array}$ & $\begin{array}{c}2 / 7(28 \%) \\
2 / 188(1.14 \%)\end{array}$ & $\begin{array}{l}0.9749 \\
0.0121\end{array}$ \\
\hline $1 \mathrm{~min}$ APGAR & $\begin{array}{c}\text { NICU } 6.2(\mathrm{sd}=2.4) \\
\text { Nursery } 8.1(\mathrm{sd}=1.5)\end{array}$ & $\begin{array}{l}4.0(\mathrm{sd}=2.9) \\
7.5(\mathrm{sd}=2.2)\end{array}$ & \\
\hline 5 min APGAR & $\begin{array}{l}\text { NICU } 7.8(\mathrm{sd}=1.4) \\
\text { Nursery } 8.8(\mathrm{sd}=1.0)\end{array}$ & $\begin{array}{l}6.7(\mathrm{sd}=1.8) \\
8.4(\mathrm{sd}=1.8)\end{array}$ & \\
\hline Birth weight & $\begin{array}{l}\text { NICU } 1559.8(\mathrm{sd}=658.0) \\
\text { Nursery } 3192.9(\mathrm{sd}=622.8)\end{array}$ & $\begin{array}{l}1105.1(\mathrm{sd}=300.3) \\
2748.1(\mathrm{sd}=839.8)\end{array}$ & \\
\hline $\begin{array}{l}\text { Respiratory support } \\
\text { duration (days) }\end{array}$ & NICU $24.46(s d=42.33)$ & $25.7(\mathrm{sd}=36.45)$ & \\
\hline Gestational age & NICU $222.8(\mathrm{sd}=31.4)$ & $227.0(\mathrm{sd}=48.7)$ & \\
\hline
\end{tabular}


the NPC and PC groups. Also, baseline primary diagnoses of the infants in both the NICU and the well-baby nursery were overall similar in the NPC and PC cohorts, except that in NICU, the NPC group showed a higher failure rate for initial audiology assessment as well as a longer duration of respiratory support, the latter contributing to a longer NICU stay (25.7 days in NPC group; 24.5 days in PC group).

\section{Conclusion for Practice}

Prenatal care is one of the most frequently used services in the United States healthcare system [14] [15] and is designed to ensure optimal maternal and fetal health [16] [17]. Prenatal care is especially important during high risk pregnancies, as it helps to establish early diagnosis and intervention for conditions that are known to present a risk to the health of the mother and the developing fetus [18] [19]. Compliance with prenatal care visits can also be indicative of appropriate parenting behaviors that include parental nurturance and readiness, both of which have been shown to be positively correlated with optimal neurodevelopmental outcomes after birth [20].

This study examined associations between prenatal care and neurodevelopmental outcomes, examined from both social and medical perspectives. Our purpose in this study is therefore two-fold. One, we attempted to compare two groups of mothers, one with prenatal care (PC) and another with complete absence of prenatal care (NPC), in order to identify specific challenges faced by NPC mothers. By better understanding such challenges, one can better provide them with opportunities to seek appropriate prenatal care by offering them both medical and non-medical assistance. Two, we attempted to show that there is a significant difference in the discharge diagnoses of infants born to mothers with and without prenatal care and that the impact of those diagnoses on neurodevelopmental outcome tends to be long lasting. Both NICU and well-baby cohorts were examined in order to demonstrate that the differences between PC and NPC groups persisted in both cohorts.

In our study, we were able to show that there was a statistically significant association between absence of prenatal care and the presence of selected social determinants such as a family's demographic profile, the mother's parity, a history intrauterine drug exposure and CPS involvement. In order to provide the social context for this study's findings, the participating patients' zip codes were compared and revealed that mothers who did not seek prenatal care were more concentrated in the areas that were further away from major acute care hospitals. These mothers also tended to be medically underserved and to be African American women of childbearing ages (15 - 44 y.o.) who earned a low income, indicating that there may be chronic mechanisms through which they are predisposed to high risk child birth. Beyerly et al. argued in their systemic reviews however that these vulnerable populations tended to show significant improvement in public health outcomes when appropriate interventions were adopted 
[19]. Thus our findings argue for implementation of relatively simple interventions for these mothers that would significantly improve outcomes for newborns including more readily available and easily accessible prenatal care. In our study, we also showed a strong association between a complete lack of prenatal care and a history of IUDE and CPS involvement. This is significant, because both IUDE and CPS involvement represent the lack of a family's readiness for childcare and can chronically affect the child's wellbeing [13]. Again, it is important to recognize that prenatal care can improve neurodevelopmental outcome by identifying this lack of readiness early in the pregnancy.

Our study also looked at an infants' discharge diagnoses as surrogates for their medical vulnerability. Our findings suggested that the primary diagnoses of the infants in both the NICU and well-baby nursery were overall similar in NPC and PC cohorts, though more infants in the well-baby newborn nursery without prenatal care required escalation of care to the NICU due to clinical deterioration than their counterparts with prenatal care. Also notable was that birth weights were lower in the NPC group in both the NICU and newborn nursery, causing them to be more susceptible to medical complications. Also, the NPC group in the NICU showed a longer duration of respiratory support, a factor that contributed to a longer NICU stay (25.7 days in NPC group; 24.5 days in PC group) and chronic pulmonary conditions requiring further medical attention later in life [21]. When these chronic pulmonary conditions co-occur with low birth weight, they can significantly compromise the health of children later on in life. This is particularly significant, as most NPC mothers in this study reside in a jurisdiction where environmental conditions in some instances may further complicate pre-existing chronic lung conditions in their children [21] [22] [23].

Another aspect of medical vulnerability that we focused on were conditions that are known to have a high correlation with neurodevelopmental delay. These include 1) leaving the hospital with discharge diagnoses that include IVH, PVL, ROP, and failed routine audiology evaluation, and 2), a requirement for CNS medications (particularly antiepileptic medications, neurotoxic substances, and caffeine) while they were inpatients. In both the nursery and the NICU, the NPC group had a higher failure rate for initial audiology assessment, a finding that can predispose these infants to developmental language delays. Meanwhile, other examples of aforementioned neurological conditions showed very similar prevalence in the NPC and PC groups in both the NICU and the well-baby nursery. Though seemingly counterintuitive, this pattern is consistent with previous studies that show development of these pathologies is strongly correlated with the infant's gestational age [21] [24], which is especially pertinent in the NICU cohort, and whose distribution was similar between NPC and PC groups. However, as mentioned earlier, this might imply that seeking and completing prenatal care appropriately can benefit the mother-infant dyad by lowering the maternal risks associated with pregnancy, potentially increasing the birth weight of the infant and lowering the risk for developing pulmonary complications [25] [26] 
[27]. With regard to a requirement for CNS medications, which in our study was exclusively caffeine, there was a higher prevalence of caffeine administration to the NPC babies in both the NICU and well-baby nursery.

In summary, our findings suggest that prenatal care can be revisited in the context of medical and social vulnerability. Understanding the relationship between lack of prenatal care and social determinants is important, because many families face numerous barriers to attending health care visits due to these social determinants and having a newborn can make these barriers more difficult to negotiate successfully [26] [27] [28] [29]. The relationship between completion of prenatal care and an infants' medical vulnerability is also important, as the resulted poor health outcome for these infants can be chronic, especially when it involves neurodevelopmental delay and further burdens the family psychosocially. And finally, our study showed a strong association between lack of prenatal care and mothers from economically vulnerable populations with barriers to accessible healthcare services. We propose that prenatal care should continue to be a priority when considering public health policy and interventions that can significantly reduce neurodevelopmental morbidity.

Several limitations of this study warrant a mention. First of all, this study is mostly focused on poor birth outcomes in the newborn and is therefore limited when it comes to maternal factors such as a mothers' education level. Also, we acknowledge that we conducted this study based on a relatively small cohort, especially those in the NICU, who were from an urban healthcare center serving a population with predominantly lower socioeconomic status. Therefore, findings should not be generalized to the general population. To address these limitations, additional research will need to be done with a larger and more heterogeneous population in order to strengthen our hypothesis.

\section{Conflicts of Interest}

The authors declare no conflicts of interest regarding the publication of this paper.

\section{References}

[1] Herbst, M.A., Mercer, B.M., Beazley, D., Meyer, N. and Carr, T. (2003) Relationship of Prenatal Care and Perinatal Morbidity in Low-Birth-Weight Infants. American Journal of Obstetrics and Gynecology, 189, 930-933.

http://www.ncbi.nlm.nih.gov/pubmed/14586328 https://doi.org/10.1067/S0002-9378(03)01055-X

[2] Adams, R.C. and Tapia, C. (2013) Early Intervention, IDEA Part C Services, and the Medical Home: Collaboration for Best Practice and Best Outcomes. Pediatrics, 132, e1073-e1088. http://pediatrics.aappublications.org/content/132/4/e1073.abstract https://doi.org/10.1542/peds.2013-2305

[3] Behnke, M. and Smith, V.C. (2013) Prenatal Substance Abuse: Short- and LongTerm Effects on the Exposed Fetus. Pediatrics, 131, e1009-e1024.

https://doi.org/10.1542/peds.2012-3931

[4] Houston, K.T., Behl, D.D., White, K.R., Forsman, I. and Zuckerman, B. (2010) Fed- 
eral Privacy Regulations and the Provision of Early Hearing Detection and Intervention Programs: TABLE 1. Pediatrics, 126, S28-S33.

https://doi.org/10.1542/peds.2010-0354G

[5] Colomar, M., Cafferata, M.L., Aleman, A., Tomasso, G. and Betran, A.P. (2017) Supply Kits for Antenatal and Childbirth Care during Antenatal Care and Delivery: A Mixed-Methods Systematic Review, the Qualitative Approach. Reproductive Health, 14, 48. https://doi.org/10.1186/s12978-017-0299-0

[6] Mbuagbaw, L., Medley, N., Darzi, A.J., Richardson, M., Habiba Garga, K. and Ongolo-Zogo, P. (2015) Health System and Community Level Interventions for Improving Antenatal Care Coverage and Health Outcomes. The Cochrane Database of Systematic Reviews, No. 12, CD010994.

https://doi.org/10.1002/14651858.CD010994.pub2

[7] Tyson, J.E., Parikh, N.A., Langer, J., Green, C., Higgins, R.D. and National Institute of Child Health and Human Development Neonatal Research Network (2008) Intensive Care for Extreme Prematurity-Moving beyond Gestational Age. The New England Journal of Medicine, 358, 1672-1681.

https://doi.org/10.1056/NEJMoa073059

[8] Hussey-Gardner, B. and Famuyide, M. (2009) Developmental Interventions in the NICU: What are the Developmental Benefits? Neoreviews, 10, e113-e120.

https://doi.org/10.1542/neo.10-3-e113

[9] Jobe, A.H. (2001) Predictors of Outcomes in Preterm Infants: Which Ones and When? The Journal of Pediatrics, 138, 153-156. https://doi.org/10.1067/mpd.2001.112760

[10] Canfield, M., Radcliffe, P., Marlow, S., Boreham, M. and Gilchrist, G. (2017) Maternal Substance Use and Child Protection: A Rapid Evidence Assessment of Factors Associated with Loss of Child Care. Child Abuse \& Neglect, 70, 11-27. https://doi.org/10.1016/j.chiabu.2017.05.005

[11] Krans, E.E. and Davis, M.M. (2014) Strong Start for Mothers and Newborns: Implications for Prenatal Care Delivery. Current Opinion in Obstetrics \& Gynecology, 26, 511-515. https://doi.org/10.1097/GCO.0000000000000118

[12] Parekh, N., Jarlenski, M. and Kelley, D. (2017) Prenatal and Postpartum Care Disparities in a Large Medicaid Program. Maternal and Child Health Journal, 22, 429-437. https://doi.org/10.1007/s10995-017-2410-0

[13] Frank, D.A., Augustyn, M. and Zuckerman, B.S. (1998) Neonatal Neurobehavioral and Neuroanatomic Correlates of Prenatal Cocaine Exposure: Problems of Dose and Confounding. Annals of the New York Academy of Sciences, 846, 40-50. https://doi.org/10.1111/j.1749-6632.1998.tb09725.x

[14] Alexander, G.R. and Kotelchuck, M. (2001) Assessing the Role and Effectiveness of Prenatal Care: History, Challenges, and Directions for Future Research. Public Health Reports, 116, 306-316. https://doi.org/10.1016/S0033-3549(04)50052-3

[15] Kotelchuck, M. (1994) An Evaluation of the Kessner Adequacy of Prenatal Care Index and a Proposed Adequacy of Prenatal Care Utilization Index. American Journal of Public Health, 84, 1414-1420. https://doi.org/10.2105/AJPH.84.9.1414

[16] Fiscella, K. (1995) Does Prenatal Care Improve Birth Outcomes? A Critical Review. Obstetrics \& Gynecology, 85, 468-479. https://doi.org/10.1016/0029-7844(94)00408-6

[17] Reichman, N.E., Corman, H., Noonan, K. and Schwartz-Soicher, O. (2010) Effects of Prenatal Care on Maternal Postpartum Behaviors. Review of Economics of the Household, 8, 171-197. https://doi.org/10.1007/s11150-009-9074-5 
[18] Gonthier, C., Estellat, C., Deneux-Tharaux, C., Blondel, B., Alfaiate, T., Schmitz, T. and Azria, E. (2017) Association between Maternal Social Deprivation and Prenatal Care Utilization: The PreCARE Cohort Study. BMC Pregnancy and Childbirth, 17, 126. https://doi.org/10.1186/s12884-017-1310-Z

[19] Byerley, B.M. and Haas, D.M. (2017) A Systematic Overview of the Literature Regarding Group Prenatal Care for High-Risk Pregnant Women. BMC Pregnancy and Childbirth, 17, 329. https://doi.org/10.1186/s12884-017-1522-2

[20] Black, M., Schuler, M. and Nair, P. (1993) Prenatal Drug Exposure: Neurodevelopmental Outcome and Parenting Environment. Journal of Pediatric Psychology, 18, 605-620. http://www.ncbi.nlm.nih.gov/pubmed/7507525 https://doi.org/10.1093/jpepsy/18.5.605

[21] Hsu, C.-T., Chen, C.-H., Lin, M.-C., Wang, T.-M. and Hsu, Y.-C. (2018) Post-Discharge Body Weight and Neurodevelopmental Outcomes among Very Low Birth Weight Infants in Taiwan: A Nationwide Cohort Study. PLOS ONE, 13, e0192574. https://doi.org/10.1371/journal.pone.0192574

[22] Hall, K.K., Chang, A.B., Anderson, J., Arnold, D., Goyal, V., Dunbar, M., O’Grady, K.-A.F., et al. (2017) The Incidence and Short-Term Outcomes of Acute Respiratory Illness with Cough in Children from a Socioeconomically Disadvantaged Urban Community in Australia: A Community-Based Prospective Cohort Study. Frontiers in Pediatrics, 5, 228. https://doi.org/10.3389/fped.2017.00228

[23] Schultz, E.S., Litonjua, A.A. and Melén, E. (2017) Effects of Long-Term Exposure to Traffic-Related Air Pollution on Lung Function in Children. Current Allergy and Asthma Reports, 17, 41. https://doi.org/10.1007/s11882-017-0709-y

[24] Thompson, D.K., Kelly, C.E., Chen, J., Beare, R., Alexander, B., Seal, M.L., Cheong, J.L.Y., et al. (2018) Early Life Predictors of Brain Development at Term-Equivalent Age in Infants Born across the Gestational Age Spectrum. NeuroImage, 185, 813-824. https://doi.org/10.1016/j.neuroimage.2018.04.031

[25] Rose, J., Vassar, R., Cahill-Rowley, K., Guzman, X.S., Stevenson, D.K. and Barnea-Goraly, N. (2014) Brain Microstructural Development at Near-Term Age in Very-Low-Birth-Weight Preterm Infants: An Atlas-Based Diffusion Imaging Study. NeuroImage, 86, 244-256. https://doi.org/10.1016/j.neuroimage.2013.09.053

[26] Neuspiel, D.R. (1994) Behavior in Cocaine-Exposed Infants and Children: Association versus Causality. Drug and Alcohol Dependence, 36, 101-107. https://doi.org/10.1016/0376-8716(94)90091-4

[27] Aylward, G.P. (2002) Methodological Issues in Outcome Studies of at-Risk Infants. Journal of Pediatric Psychology, 27, 37-45. https://doi.org/10.1093/jpepsy/27.1.37

[28] Cross-Barnet, C., Courtot, B., Hill, I., Benatar, S., Cheeks, M. and Markell, J. (2018) Facilitators and Barriers to Healthy Pregnancy Spacing among Medicaid Beneficiaries: Findings from the National Strong Start Initiative. Women's Health Issues, 28, 152-157. https://doi.org/10.1016/j.whi.2017.12.004

[29] Little, D.S. (2016) 2014 Infant Mortality Report. Data Management and Analysis Division, Center for Policy, Planning, and Evaluation. Department of Health, Government of the District of Columbia.

https://doh.dc.gov/sites/default/files/dc/sites/doh/publication/attachments/IMR_20 14_Edits_6.19.17.pdf 